\title{
Evaluation of some heavy metal contaminants in biscuits, fruit drinks, concentrates, candy, milk products and carbonated drinks sold in Ibadan, Nigeria
}

\author{
Racheal Adebola ADEGBOLA*, Adewumi Iyabode ADEKANMBI, Dupe Lydia ABIONA \\ and Azeezat Ayannike ATERE
}

Chemistry Department, The Polytechnic, Ibadan, Ibadan, Nigeria.

*Corresponding author, E-mail: bolaboyinadegbola@gmail.com, Tel: +234 08055159487

\begin{abstract}
There is an increasing concern about the health effect in human due to continual consumption of food contaminated with heavy metals gotten from raw materials, manufacturing and packaging processes. It is therefore crucial to know the level of heavy metals in them because of its bio-accumulative property. A total of twelve (12) different brands of sweet and milk sweets, six different brands of biscuits, eleven different brands of fruit and flavoured concentrates and five different types of liquid drinks all of popular brands were collected. All the samples were cold digested using concentrated hydrochloric acid and nitric acid in ratio 1:1. The extracts were analysed for calcium, chromium, copper, iron, lead, and cadmium with Perkin Elmer (A Analyst 200) Flame Atomic Absorption Spectrophotometer. Appropriate quality assurance procedures were followed to ensure accuracy of results. Results showed that calcium and iron were present in all the samples analysed while chromium, copper, lead and cadmium were not detected in some samples. Calcium had higher concentration than other heavy metals in all the samples. Concentrations of these metals in all the samples were found to be lower than their permissible limits, which implied non contamination hence no health threat to human, but continuous consumption may be hazardous to the health.
\end{abstract}

(C) 2015 International Formulae Group. All rights reserved.

Keywords: Hazardous, bio-accumulative, contamination.

\section{INTRODUCTION}

Ingestion of food is an obvious means of exposure to metals not only because many are natural components of foodstuff but also because of contamination during processing. Contamination of food products by heavy metals is becoming an unavailable problem. These agents have led to metal depression in the environment and consequently impaired health of the population by ingestion of contaminated victuals (Zukowska and Bizink, 2008). Determination of metals in samples is to resolve issues such as mineral contents, adulteration of raw materials used, compliance with trade laws and safety of the final product for consumption and its effect if contaminated.

In the present era of industrialization and development, one's concern should be the health of the future generation. Children are the most vulnerable to any kind of contamination in the food chain (Farid and Enani, 2010). Due to economic situation in 
Nigeria, young children between ages 6 months and 13 years had been exposed to different types of snacks majorly sweets, biscuits, carbonated fruit drinks, milk shakes and milk sweets. Most heavy metals are introduced through the packaging when the candies surfaces are sticky allowing the surface of the candy adhere to the inner cover of the package.

Heavy metals occur in foods as natural or inherent components of plant and animal tissue and fluid. The essential metals (e.g. Mn, $\mathrm{Cu}, \mathrm{Zn}, \mathrm{Cd}$ ) own their essentiality being constituents of enzymes and other important proteins involved in key metabolic pathways, hence, deficient supply results into metabolic dysfunction causing diseases (Iwegbue, 2008). Although many heavy metals are essential for animal tissue metabolism, the ranges between beneficial and toxic level are usually small. The extent of this contamination depends on several metabolic and homeostatic mechanisms operating in the type of food and tissue considered (Jorhem and Sundstroem, 2000; Chukwujindu et al., 2008).

Heavy metals are persistent as contaminants in the environment and come to the forefront of dangerous substances causing healthy hazard in human. Lead, cadmium, mercury and tin are among the most important of these elements. Industrial and agricultural processes have resulted in an increased concentration of heavy metals in air, water, soil and subsequently, these metals are taken by plants or animals and have their ways into food chain (Ahmad, 2002). Chromium is important in the utilization of glucose, therefore its deficiency causes a decrease in glucose tolerance and increase in cardiovascular diseases. Deficiency in calcium can cause serious structural disorders due to its involvement in the structure of the muscular system.

Food products such as candies that are likely to be consumed frequently by small children are wrapped in colourful packages in order to induce them to purchase the products.
Heavy metals, such as $\mathrm{Pb}, \mathrm{Cr}, \mathrm{Ti}, \mathrm{Zn}$ and $\mathrm{Cu}$ can migrate from the printed surface to the food contact surface through four mechanisms: blocking, rubbing, peeling and diffusion (Bradley et al., 2005). Contamination of imported food products with heavy metals may cause a serious risk for human health because of the consumption of even small amount of metals can lead to considerable concentrations in human body there leading to bio-toxic effects. Juices are the perfect fast-food for today's eat-on the- run lifestyle. They contain all the goodness of the whole product in a condensed form. 100\% juices are a convenient way for adults and children to get a part of their recommended 4.5 or more cups of fruits and vegetables each day. Milk is an ideal source of microelements and macroelements, additional amount of contaminants metals might enter milk and dairy products reaching levels that are harmful to humans (Qin et al., 2009) through foodstuff, water, manufacturing and packaging processes (Anastasio et al., 2006; Ayar et al., 2009). Fruits and hence fruit juices and vegetables are valuable sources of minerals. Diets high in fruits and vegetables are also linked to decreased risk of diseases (diabetes, cancer, etc.) and their consumption should be encouraged (Simpkins et al., 2000). This study was undertaken to determine the concentrations of some trace elements in fruit drinks, concentrates, candy, milk products and carbonated drinks.

\section{MATERIALS AND METHODS Sample collection}

A total of twelve (12) different brands of sweet and milk sweets, six different brands of biscuits, eleven different brands of fruit and flavoured concentrates and five different types of liquid drinks was selected. The selection was specially made to reflect the popular brands consumed by different age groups especially children. The samples were stored at almost identical conditions similar to those of retail shops prior analysis. 


\section{Sample preparation and digestion}

The solid samples were ground with a pre-cleaned porcelain mortar and pestle. Cold digestion (i.e. digestion was done without application of heat) was used for all the samples.

\section{Solid and liquid samples}

For solid samples, an accurately measured weight of $5 \mathrm{~g}$ of each sample was transferred into a flask; $10 \mathrm{ml}$ of concentrated hydrochloric acid and $10 \mathrm{ml}$ of nitric acid were added and allowed to stay for 18 hours in a fume cupboard. For liquid samples, a volume of $5 \mathrm{ml}$ of each sample was accurately measured and transferred into a flask; $10 \mathrm{ml}$ of concentrated hydrochloric acid and $10 \mathrm{ml}$ of nitric acid were added and allowed to stay for 18 hours in a fume cupboard.

The digested samples were filtered. The filtrate was transferred into a $100 \mathrm{ml}$ standard flask and made up to mark with distilled water which was later transferred into a plastic sample bottles. All the filtrates were analysed for calcium, chromium, copper, iron, lead, and cadmium with Perkin Elmer (A Analyst 200) flame atomic absorption spectrophotometer. A fuel clean Air-Acetylene flame was used. The metals were determined at the most sensitive spectral lines of the metals.

\section{RESULTS}

Table 1 showed the varying levels of the heavy metals in the sweet samples. Highest Cadmium concentration was found in sample A11 $(0.09 \pm 0.010 \mathrm{mg} / \mathrm{L})$ while the lowest was recorded in sample A1 $(0.00 \pm 0.008 \mathrm{mg} / \mathrm{L})$. Cadmium was not detected in samples A2, A3, A4, A5, A6, and A7.

Table 2 showed the concentration of heavy metals in biscuit samples analysed, with the highest concentration of Cadmium found in B2 $(0.09 \pm 0.047 \mathrm{mg} / \mathrm{L})$ while B6 $(0.003 \pm 0.038 \mathrm{mg} / \mathrm{L})$ recorded the lowest concentration. Lead concentration was not detected in sample B1 and B2. Table 3 showed the concentration of heavy metals in milk candy and fruit concentrate samples analysed. Chromium was not detected in samples $\mathrm{C} 9$ and $\mathrm{C} 10$, lead was not detected in $\mathrm{C} 8$ and $\mathrm{C} 9$ while cadmium was not detected in sample $\mathrm{C} 11$.

Table 4 shows the concentration of the heavy metals detected in juice and milk shakes samples with the lowest concentration observed in copper for all the samples analysed.

Table 1: Concentration (mg/l) of heavy metals in sweets samples.

\begin{tabular}{lcccccc}
\hline Sample & $\mathbf{C a}$ & $\mathbf{C r}$ & $\mathbf{C u}$ & $\mathbf{F e}$ & $\mathbf{P b}$ & $\mathbf{C d}$ \\
\hline A1 & $34.0 \pm 0.12$ & $0.04 \pm 0.061$ & $0.01 \pm 0.002$ & $3.42 \pm 0.52$ & $0.90 \pm 0.069$ & $0.00 \pm 0.008$ \\
$\mathrm{~A} 2$ & $10.9 \pm 0.033$ & $\mathrm{ND}$ & $0.04 \pm 0.002$ & $1.52 \pm 0.003$ & $0.39 \pm 0.052$ & ND \\
$\mathrm{A} 3$ & $14.9 \pm 0.12$ & $\mathrm{ND}$ & $0.04 \pm 0.002$ & $1.00 \pm 0.000$ & $0.17 \pm 0.054$ & $0.00 \pm 0.018$ \\
$\mathrm{~A} 4$ & $5.50 \pm 0.013$ & $\mathrm{ND}$ & $0.04 \pm 0.002$ & $1.67 \pm 0.010$ & $0.16 \pm 0.031$ & ND \\
A5 & $14.6 \pm 0.016$ & $0.02 \pm 0.027$ & ND & $0.67 \pm 0.062$ & $0.03 \pm 0.041$ & ND \\
A6 & $29.4 \pm 0.11$ & $0.06 \pm 0.073$ & ND & $1.01 \pm 0.005$ & $0.04 \pm 0.054$ & ND \\
A7 & $7.40 \pm 0.036$ & $0.07 \pm 0.018$ & $0.11 \pm 0.074$ & $1.58 \pm 0.005$ & $0.01 \pm 0.008$ & ND \\
A8 & $3.90 \pm 0.009$ & $0.02 \pm 0.067$ & $0.17 \pm 0.001$ & $2.21 \pm 0.022$ & ND & $0.04 \pm 0.032$ \\
A9 & $16.3 \pm 0.015$ & ND & ND & $0.91 \pm 0.017$ & ND & $0.03 \pm 0.005$ \\
A10 & $20.9 \pm 0.005$ & $0.21 \pm 0.034$ & ND & $0.52 \pm 0.009$ & ND & $0.09 \pm 0.026$ \\
A11 & $13.1 \pm 0.007$ & $0.50 \pm 0.017$ & $0.02 \pm 0.004$ & $1.76 \pm 0.009$ & ND & $0.09 \pm 0.010$ \\
A12 & $32.6 \pm 0.021$ & $0.25 \pm 0.004$ & $0.01 \pm 0.001$ & $0.71 \pm 0.013$ & ND & $0.06 \pm 0.038$ \\
\hline \multicolumn{2}{r}{ Mean + SD ND: Not Detected }
\end{tabular}


Table 2: Concentration (mg/L) of heavy metals in biscuit samples.

\begin{tabular}{lcccccc}
\hline Sample & $\mathbf{C a}$ & $\mathbf{C r}$ & $\mathbf{C u}$ & $\mathbf{F e}$ & $\mathbf{P b}$ & $\mathbf{C d}$ \\
\hline B1 & $3.2 \pm 0.028$ & $0.25 \pm 0.022$ & $0.51 \pm 0.012$ & $1.36 \pm 0.006$ & ND & $0.07 \pm 0.028$ \\
B2 & $2.90 \pm 0.011$ & $0.18 \pm 0.017$ & $0.13 \pm 0.006$ & $1.58 \pm 0.031$ & ND & $0.09 \pm 0.047$ \\
B3 & $1.4 \pm 0.004$ & $0.17 \pm 0.007$ & $0.13 \pm 0.001$ & $1.41 \pm 0.005$ & $0.06 \pm 0.031$ & $0.01 \pm 0.007$ \\
B4 & $6.8 \pm 0.16$ & $0.12 \pm 0.026$ & $0.15 \pm 0.001$ & $2.07 \pm 0.040$ & $0.08 \pm 0.024$ & $0.05 \pm 0.036$ \\
B5 & $8.9 \pm 0.012$ & $0.16 \pm 0.010$ & $0.12 \pm 0.001$ & $1.64 \pm 0.019$ & $0.06 \pm 0.015$ & $0.03 \pm 0.004$ \\
B6 & $10.1 \pm 0.006$ & $0.13 \pm 0.002$ & $0.08 \pm 0.001$ & $1.02 \pm 0.012$ & $0.01 \pm 0.022$ & $0.003 \pm 0.038$ \\
\hline
\end{tabular}

Mean \pm SD, ND: Not Detected

Table 3: Concentration $(\mathrm{mg} / \mathrm{L})$ of heavy metals in milk candy and fruit concentrate samples.

\begin{tabular}{|c|c|c|c|c|c|c|}
\hline Sample & $\mathbf{C a}$ & $\mathrm{Cr}$ & $\mathbf{C u}$ & $\mathbf{F e}$ & $\mathbf{P b}$ & $\mathbf{C d}$ \\
\hline $\mathrm{C} 1$ & $7.70 \pm 0.014$ & $0.001 \pm 0.035$ & $1.17 \pm 0.016$ & $0.61 \pm 0.016$ & $0.05 \pm 0.003$ & $0.04 \pm 0.020$ \\
\hline $\mathrm{C} 2$ & $35 \pm 0.014$ & $0.001 \pm 0.012$ & $0.07 \pm 0.005$ & $0.91 \pm 0.006$ & $0.23 \pm 0.00$ & $.02 \pm 0.001$ \\
\hline $\mathrm{C} 3$ & $32 \pm 0.067$ & $0.0005 \pm 0.027$ & $0.05 \pm 0.005$ & $1.42 \pm 0.026$ & $0.21 \pm 0.020$ & $0.02 \pm 0.010$ \\
\hline $\mathrm{C} 4$ & $34.1 \pm 0.012$ & $0.0007 \pm 0.007$ & $3.68 \pm 0.009$ & $1.94 \pm 0.012$ & $0.11 \pm 0.007$ & $0.02 \pm 0.00$ \\
\hline $\mathrm{C} 5$ & $26.8 \pm 0.073$ & $0.0009 \pm 0.013$ & $0.10 \pm 0.006$ & $0.72 \pm 0.033$ & $0.20 \pm 0.030$ & $0.07 \pm 0.038$ \\
\hline C6 & $20.2 \pm 0.013$ & $0.0007 \pm 0.004$ & $0.09 \pm 0.003$ & $0.70 \pm 0.010$ & $0.25 \pm 0.014$ & $0.07 \pm 0.053$ \\
\hline $\mathrm{C} 7$ & $8.00 \pm 0.006$ & $0.0003 \pm 0.000$ & $0.08 \pm 0.013$ & $0.46 \pm 0.022$ & $0.01 \pm 0.033$ & $0.03 \pm 0.014$ \\
\hline $\mathrm{C} 8$ & $20.6 \pm 0.006$ & $0.0004 \pm 0.034$ & $0.59 \pm 0.11$ & $0.97 \pm 0.015$ & ND & $0.02 \pm 0.042$ \\
\hline C9 & $49.1 \pm 0.013$ & ND & $0.02 \pm 0.010$ & $1.99 \pm 0.008$ & ND & $0.04 \pm 0.025$ \\
\hline $\mathrm{C} 10$ & $44.9 \pm 0.086$ & ND & $0.01 \pm 0.002$ & $0.94 \pm 0.010$ & $0.06 \pm 0.89$ & $0.06 \pm 0.003$ \\
\hline $\mathrm{C} 11$ & $14.3 \pm 0.13$ & $0.0003 \pm 0.023$ & $0.02 \pm 0.010$ & $0.61 \pm 0.004$ & $0.08 \pm 0.0041$ & ND \\
\hline $\mathrm{C} 12$ & $6.40 \pm 0.13$ & $0.0005 \pm 0.001$ & $0.01 \pm 0.00$ & $0.94 \pm 0.23$ & $0.28 \pm 0.028$ & $0.04 \pm 0.003$ \\
\hline
\end{tabular}

Table 4: Concentration $(\mathrm{mg} / \mathrm{L})$ of heavy metals in juice and milk shake samples.

\begin{tabular}{lcccccc}
\hline Sample & $\mathbf{C a}$ & $\mathbf{C r}$ & $\mathbf{C u}$ & $\mathbf{F e}$ & $\mathbf{P b}$ & $\mathbf{C d}$ \\
\hline D1 & $3.0 \pm 0.074$ & $0.57 \pm 0.001$ & $0.03 \pm 0.003$ & $1.88 \pm 0.031$ & $0.37 \pm 0.038$ & $0.03 \pm 0.026$ \\
D2 & $7.4 \pm 0.001$ & $0.18 \pm 0.013$ & $0.02 \pm 0.000$ & $0.88 \pm 0.003$ & $0.29 \pm 0.032$ & $0.11 \pm 0.013$ \\
D3 & $0.18 \pm 0.013$ & $0.09 \pm 0.001$ & $0.03 \pm 0.004$ & $0.66 \pm 0.002$ & $0.20 \pm 0.052$ & $0.12 \pm 0.029$ \\
D4 & $34.1 \pm 0.012$ & $0.08 \pm 0.004$ & $0.01 \pm 0.002$ & $0.50 \pm 0.013$ & $0.39 \pm 0.007$ & $0.08 \pm 0.001$ \\
D5 & $26.8 \pm 0.073$ & $0.06 \pm 0.013$ & $0.02 \pm 0.000$ & $0.55 \pm 0.023$ & $1.21 \pm 1.04$ & $0.11 \pm 0.015$ \\
\hline
\end{tabular}

\section{DISCUSSION}

The result showed that calcium and iron which are part of the microelements that are necessary as components of enzymes involved in major metabolic processes were present in all the samples analysed. Chromium, copper, lead and cadmium were not detected in some samples. It was also observed that calcium has higher concentration than other heavy metals present in the samples (Table 1-4).

Also the results showed that cadmium concentration in all the samples did not exceed the permissible level of $1.5 \mathrm{mg} / \mathrm{kg}$ (CAC, 2003). Although the concentration present may be attributed to sachet used in the sweet packaging which is in accordance with Ki-Cheol et al. (2008), whose results 
demonstrated that harmful pigments such as lead chromate, which have been prohibited by law from being used in packaging materials are still being used. Highest lead concentration was found in sample A2 $(0.39 \pm 0.052 \mathrm{mg} / \mathrm{kg})$ while sample A7 $(0.01 \pm 0.008 \mathrm{mg} / \mathrm{kg})$ recorded the lowest lead concentration. Lead concentration in all the samples did not exceed the maximum permissible limit of $2.5 \mathrm{mg} / \mathrm{kg}$ (CAC, 2003). Calcium and iron were found to be present in all the samples and the result were found to be in line with Iwegbue (2012).

Varying levels of calcium, chromium, copper, and iron was recorded in all the samples while lead levels were not detected in sample B1 and B2. The results revealed that all the heavy metals concentrations were within the acceptable limit of food (CAC, 2003), while heavy metals concentrations in fruit concentrates, milk candies and milk shakes were also below the permissible limits (JEFCA, 2010).

Possible explanation for the presence of heavy metals in the samples analysed are contamination of the raw materials used, manufacturing and packaging processes (Ashraf, 2006).

\section{Conclusion}

This study was able to establish that all heavy metals tested for were below permissible limit in all the samples analysed. These indicated that the samples were not contaminated and pose no damage to human health, though consistent intake of these products can be hazardous due to the bioaccumulative property of heavy metals. The results also showed that calcium and iron which are part of the microelements necessary as components of enzymes involved in major metabolic processes were present in all the samples analysed. It is recommended that constant monitoring of raw materials used should be carried out during manufacturing and also packaging process should be monitored in order to avoid the levels exceeding permissible limits.

\section{REFERENCES}

Ahmad WMS. 2002. Studies on heavy metal pollution in poultry farms in relation to production performance. $\mathrm{Ph}$. D. Thesis Faculty Of Vet. Med. Gonzaga University, xii $+165 p p$.

Anastastio A, Caggiano R, Macciato M, Paolo CI, Ragosta M, Cortesi ML. 2006. Heavy concentration in dairy products from sheep milk collected in two regions of Southern Italy. Acta veterinaria Scandinavica, 47: 69 - 74 .

Ashraf W. 2006. Levels of selected heavy metals in Tuna fish. Arabian J. Sci. Eng., 31: 89-92.

Ayar A, Sert D, Akin N. 2009. The trace levels in milk and dairy products consumed in middle Analolia-Turkey. Environmental Monitoring Assessment, 152: 1-12.

Bradley EL, Castle L, Dines TJ, Fitzgerald AG, Gonzalez TP, Jickells SM. 2005. Test method for measuring non-visible set-off from inks and lacquers on the food contact surface of printed packaging materials. Food Additives and Contaminants, 22(5): 490-502.

CAC. 2003. Evaluation of certain food additive and contaminants. FAO/WHO, Codex standards, Rome.

Chukwujindu IF, Iwegue MA, Nwozo DO, Ossai, EK, Nwogu, GE. 2008. Heavy metal composition of some imported canned fruit drinks in Nigeria. American Journal Food Technology, 3: 220-223.

Goldfrank LR, Osborn H, Hartnett L. 1990. Lead. In Goldfrank's Toxicological Emergencies, Goldfrank LR, Flomentbaum NE, Lewin NA, Weisman RS, Howland MA (Eds). Prentice-Hall International Inc. New Jersey, USA; 627637. 
Iwegbue CM, Nwozo SO, Ossai EK, Nwajei GE. 2008. Heavy metal composition of some imported canned fruit drinks in Nigeria. American Journal of Food Technology, 3: 220-223.

JECFA. 2010. Evaluation of certain food additives and contaminants. Seventy third meeting. Summary and conclusions. JEFCA/73/SC.

Jorhem I, Sunderstroem B. 2000. Level of lead, cadmium, zinc, copper, chromium, nickel and manganese in foods on the Swedish market. Journal of Food Composition Analysis, 6: 223-241.

Kocak SO, Taksoglu L, Aycan S. 2005. Some heavy metals and trace essential element detection in canned vegetable foodstuffs by differential pulse polarography. Journal of Environment Agricultural Food Chemistry, 4: 371.

Qin LQ, Wang XP, Li W, Tong X, Tong WJ. 2009. The minerals and heavy metals in cow's milk from China and Japan. Journal Health Science, 55(2): 300-305.

Simpkins WP, Louie H, Wu M, Harrison M, Goldberg D. 2000. Trace elements in Australian orange juice and other products. Food Chemistry, 74: 423-433.

Zukowska J, Bizink M. 2008. Methodological Evaluation of Method for Dietary Heavy metal Intake. Journal of Food Science, 73(2): 21 - 29. 